\title{
Student Perspectives of Computer Literacy Education in an International Environment
}

\author{
Simona Vasilache \\ Graduate School of Systems and Information Engineering, University of Tsukuba, Japan
}

Copyright $(2016$ by authors, all rights reserved. Authors agree that this article remains permanently open access under the terms of the Creative Commons Attribution License 4.0 International License

\begin{abstract}
Computer literacy education is an integral part of early university education (it often starts at the high school level). A wide variety of university course structures and teaching styles exist and, at the same time, the knowledge levels of incoming students are varied. This issue is even more pressing in an international environment. This paper offers students' perspectives on computer literacy education in such an international environment. Based on the author's experience in a computer literacy course and on a questionnaire given to the course participants, the paper aims to identify teaching styles to which students respond positively, as well as LMS functionalities that most students accept or prefer to use during computer literacy related classes.
\end{abstract}

Keywords Computer Literacy Education, Learning Management System, International Students

\section{Introduction}

As computers and information technology devices become more and more present in all aspects of our daily life, the majority of universities in Japan include a mandatory course teaching basic computer literacy elements in the early study years. This paper will bring up two important aspects related to the development of computer literacy education: variety in course structure and styles and use of Learning Management Systems.

Before explaining in detail the two aspects, a definition of computer literacy is needed. Computer literacy has an important place as one of many forms of "literacy" [1]. Literacy in general refers to familiarity with a given subject. According to Poynton, the term "literacy" has changed within the past decades: more than 30 years ago it was defined by Webster's New World Dictionary (1984) as " the ability to read and write', whereas in the year 2000, The American Heritage Dictionary of the English Language defined literacy as "The condition or quality of being knowledgeable in a particular subject or field" [2].
Tsai defines computer literacy as "the basic knowledge, skills, and attitudes needed by all citizens to be able to deal with computer technology in their daily life" [3]. In this context, computer literacy can be defined as the ability to interact with a computer [2].

The first aspect of computer literacy education deals with course structures and teaching styles. These vary greatly across universities: each institution decides its own curriculum and employs its own method of teaching. At the same time, the knowledge levels of incoming students to the university are also varied. This is particularly true in an international environment, where students come from a multitude of countries, with various computer literacy levels in their respective countries, as well as different personal experiences with computers and information technology in general.

As shown by Wada and Takahashi [4], students entering universities in Japan display "significant disparities in computer skills". Moreover, basic academic ability in the use of information technology shows a larger disparity than academic ability in other general subjects. The same trend has been observed with regard to international students entering Japanese universities. The increasing multicultural nature of world education makes it crucial that instructors "develop skills to deliver culturally sensitive and culturally adaptive instruction" [5].

The second aspect deals with Learning Management Systems (LMS), which represent "one approach to the application of computers to education" [6]. As software programs that support learning, LMSs have become more and more widely used in teaching courses, with computer literacy courses being no exception. These courses represent a suitable medium to enable the students to familiarize themselves with the use of LMSs and encourage their use with other courses.

While "a dramatic increase in applied Learning Management System (LMS) in higher education" has been observed (according to [7]), there are significant differences in the way these LMSs are used. Moreover, incoming students present various degrees of familiarity with such systems. Some freshmen may be familiar with one single 
LMS, while others may have encountered several different ones in the online world. At the same time, there are incoming students who have no experience of using such a system. The variety of experience extends even more when the backgrounds of international students are taken into consideration. Furthermore, the perceptions and use of LMSs have a cultural dimension as well, as it was identified by Basioudis, de Lange, Suwardi and Wells [8].

In view of the above-mentioned differences and disparities, the author believes that the current methods of teaching computer literacy classes are not suitable for accommodating a large variety of students, with various cultural backgrounds. Furthermore, LMSs are not used to their full potential in the context of computer literacy education. This paper aims to identify some specific methods (to be used during computer literacy classes) that may be accepted or perceived as useful by students coming from a wide variety of backgrounds, as well as some features that may make LMSs more attractive to these students.

The remainder of the paper describes the used method, along with the results and a discussion of these results; the final section offers conclusions and describes possible directions for future work.

\section{Description of Method}

A study was conducted on a number of 42 international students enrolled in undergraduate programs taught entirely in English, at the University of Tsukuba in Japan. The participants were first-year students belonging to social sciences or life and environmental sciences, coming from more than 20 different countries on 4 continents (mostly fresh high-school graduates, aged between 18 and 19 years old). The students were enrolled in two computer literacy classes, mandatory for all freshmen at the University of Tsukuba. The two classes (called "Information Literacy I" and "Information Literacy II", respectively) were offered at two different colleges, but they delivered the same content and were conducted in the same manner, by the same instructor.

The regular computer literacy classes followed a lecture-style setting, in which the class instructor teaches the new topic(s), while students listen and ask questions when needed. One experimental lecture was held as follows. First, the students were given printed materials prepared beforehand by the class instructor, covering a new topic. The same materials were simultaneously available through the course page of manaba, the LMS currently used by the University of Tsukuba ([9]). The students spent the first 20 minutes of the experimental class on studying the materials individually, at their own pace. This was followed by 10 minutes of discussing the new topics in groups. Finally, the instructor clarified the questions the students posed.

At the end of the experimental class, the participants anonymously filled in a questionnaire consisting of 17 questions: 12 close-ended questions and 5 open-ended questions.

\section{Results and Discussion}

In the first section of the questionnaire, the students were asked their opinions with regard to the experimental class they just attended. Before answering questions directly related to this class, the respondents were asked about their experience with various styles of teaching. They were allowed to choose more than one answer, and 7 students chose to do that (one student did not reply at all to this question). More than half of the students (23) are generally accustomed to sitting in class and listening to the instructor teach new concepts (without any previous preparation on their part). 16 students have some experience with classes for which they have to study beforehand, whereas only 9 students stated that they are familiar with studying new concepts by themselves, then attending classes in which they can ask questions and clarify their ideas.

Regarding the experimental one-time class, the participants were asked to compare it with the other classes and state whether it was more challenging than usual, the same as most other classes or less challenging than usual. A similar question was posed with regard to how interesting/enjoyable the class was. Figure 1 illustrates the answers to these two questions. 


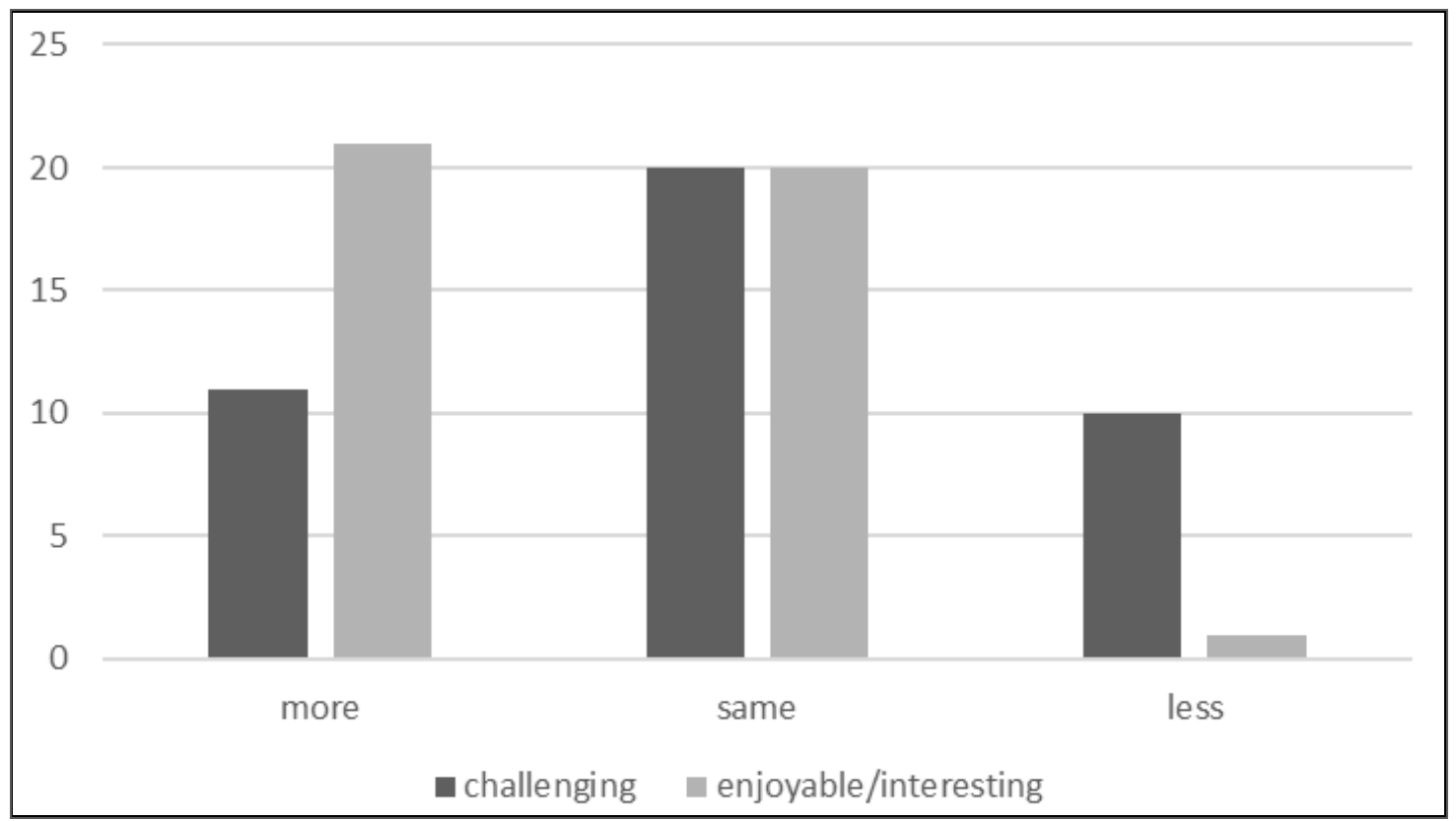

Figure 1. Experimental vs usual class comparison

As can be observe from the graph, approximately half of the respondents (20) found the experimental class equally challenging as the usual classes. "More challenging" and "less challenging" were almost equally distributed among students (11 and 10, respectively). When it comes to how enjoyable/interesting the experimental class was, as opposed to the other usual classes, the same number (20 respondents) found it equally enjoyable/interesting. However, 21 respondents found it more enjoyable/interesting than the other ones, whereas only one respondent found it less enjoyable/interesting than the usual classes, illustrating that the students respond positively to a different style of teaching, even though it may become more challenging.

We performed the chi-square test in order to evaluate the correlation between the number of students who found the class challenging and the number of students who found it enjoyable/interesting. The chi-square score is 10.4781 . The calculated $p$-value is 0.005305 . This shows that our result is significant at $p<0.05$. We can thus reject the null hypothesis and state that the two variables are dependent of each other: the number of students who find the class more enjoyable/interesting depends on the number of students who find it more challenging. This is an encouraging result, supporting the idea that the students enjoy classes which pose challenges, they find these classes more interesting.

When asked what their preferred style of teaching would be, 6 students stated that they preferred the classical style, in which the teacher introduces new concepts in class, whereas 9 students stated that they preferred the experimental class style (in which they read the new material by themselves, after which they discuss and ask questions). 27 students expressed their preference towards a combination of the above.

Some of the students took the opportunity of explaining their choice. They preferred the classical style because they are more familiar with it (one respondent) and because it is more useful when the concepts are difficult to understand (two respondents), for instance through various illustrations of these concepts offered by the teacher. The experimental style was preferred because it is easier to read at one's own pace (two respondents) and because discussions force the participants to be more active or to think critically (three respondents).

As for the combination of styles, it was preferred because it is "interesting", "refreshing", as well as because it could be adapted to the contents: the teacher should explain the more difficult topics, self-study should be used when the concepts are easier to understand, and discussions should be adopted in case of controversial topics.

The participants were also asked what they most liked and what they least liked about the experimental class (they were allowed to choose multiple answers). The results are summarized in Table 1.

Table 1. Features most/least liked during the experimental class

\begin{tabular}{|c|c|c|c|}
\hline & $\begin{array}{c}\text { Reading at } \\
\text { own pace }\end{array}$ & $\begin{array}{c}\text { Discussing } \\
\text { with others }\end{array}$ & $\begin{array}{c}\text { Asking } \\
\text { questions } \\
\text { afterwards }\end{array}$ \\
\hline $\begin{array}{c}\text { Most liked } \\
\text { feature }\end{array}$ & 7 & 33 & 5 \\
\hline $\begin{array}{c}\text { Least liked } \\
\text { feature }\end{array}$ & 20 & 8 & 5 \\
\hline
\end{tabular}

Two other items were listed as most liked by the students: the fact that they were forced to think critically and the moment when the teacher explained the new notions. The former one comes in favour of this type of classes, where students have to read, understand (and critically think about) the materials by themselves. The latter, one can argue, is actually an expression of the respective participant's preference for the classical type of classes: (s)he enjoyed 
most the part where the teacher explained, i.e. the part where the class resembled the classical style most (not any of the other individual or group activities, where the students have to understand and/or discuss the new concepts before they are taught by the instructor).

Several other least liked features were listed by the respondents: "silence" (referring to the quiet nature of the first part of the class, when students were studying the materials), not understanding enough to ask questions, not enough detailed information, contents already known. It is not difficult to observe that the items related to the contents of the materials are not directly related to the style employed in the experimental class.

One student responded that they simply preferred the other classes (in effect listing the class itself as the least liked feature of it). Two respondents stated that there was nothing in particular that they did not like about the class.

Regarding the evaluation of computer literacy classes in general, the students were asked about their preferred method: one final test, two tests (each covering half of the course), short weekly quizzes or other methods. The results are summarized in Figure 2.

The next section of the questionnaire gathered information about previous experience of using a learning management system (LMS) in general, followed by various questions with regard to manaba, i.e. the LMS currently employed at the
University of Tsukuba. Out of the 42 students questioned, 16 have never used a LMS before (manaba being the first one they ever used), 20 have some experience of using at least one other LMS, while only 6 are familiar with several different LMSs (on average, one in seven students).

Table 2 shows the frequency of accessing manaba by the surveyed students. 11 respondents access it at least once a day, 24 respondents access it 2-4 times a week, whereas 7 respondents access it once or less than once a week. No students reported using manaba "almost never".

The above results are consistent with those observed by Vasilache in [10], which focused on the impact of using a Japanese/English learning management system on the studying habits of non-native English speaking international students in Japan.

Table 2. Frequency of use of manaba

\begin{tabular}{|c|c|c|c|c|c|}
\hline & $\begin{array}{c}\text { At least } \\
\text { once a } \\
\text { day }\end{array}$ & $\begin{array}{c}2-4 \\
\text { times a } \\
\text { week }\end{array}$ & $\begin{array}{c}\text { Once a } \\
\text { week }\end{array}$ & $\begin{array}{c}\text { Less than } \\
\text { once a } \\
\text { week }\end{array}$ & $\begin{array}{c}\text { Almost } \\
\text { never }\end{array}$ \\
\hline $\begin{array}{c}\text { Number of } \\
\text { respondents }\end{array}$ & 11 & 24 & 4 & 3 & 0 \\
\hline
\end{tabular}

When asked what kind of classes they use manaba for, only one student responded that (s)he uses it for information literacy classes only; the remaining 41 students use it for several different classes.

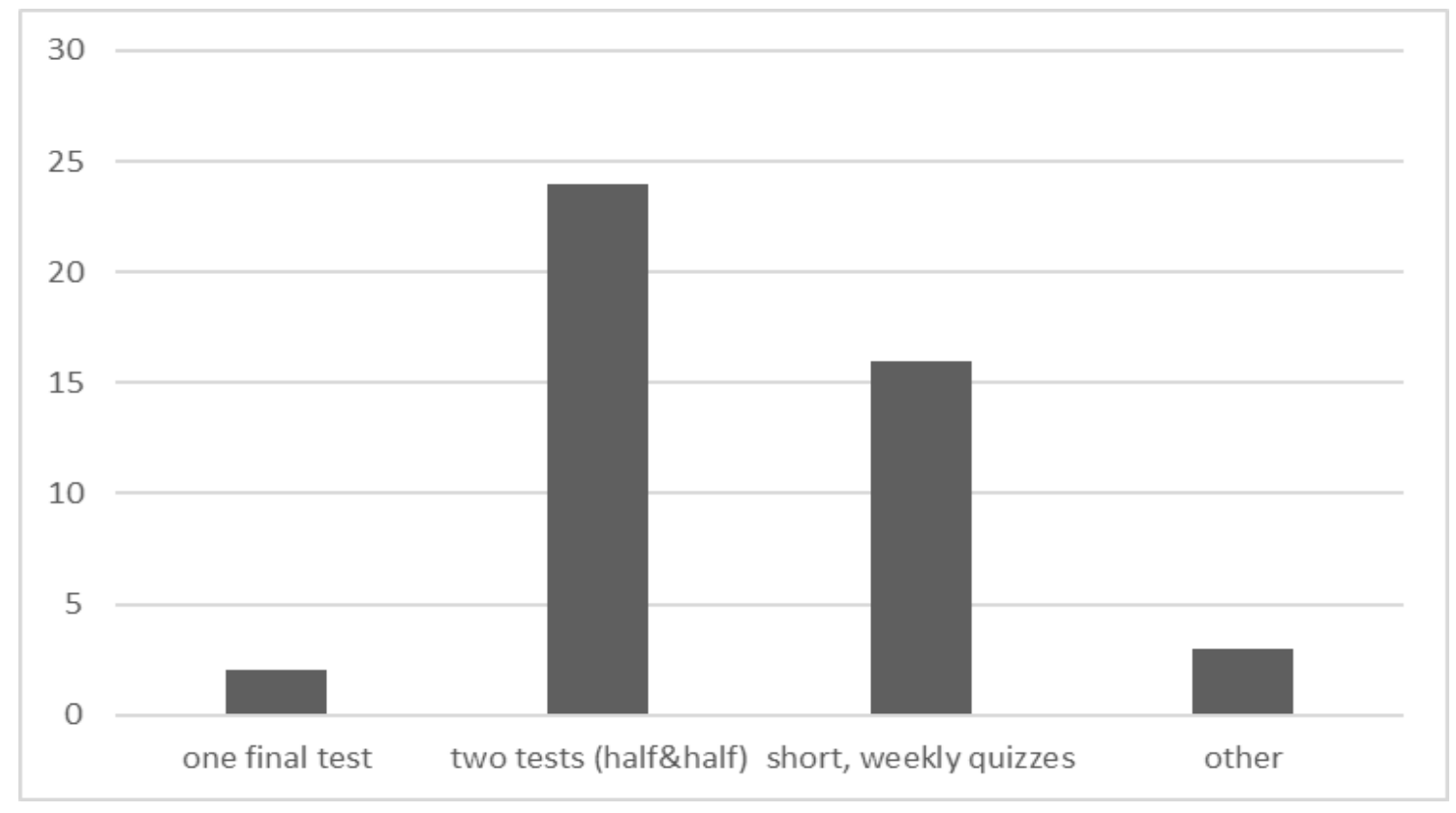

Figure 2. Preferred method of evaluation for information literacy class 
With regard to comparing the functionality most often used on manaba for information literacy classes with the functionality most often used for other classes, the results are summarized in Figure 3. In the case of information literacy classes, the majority of students use manaba for downloading course materials, followed by submitting assignments. The same two functions are mostly used for other courses, as well, but in reverse order. Communication with teachers in charge is slightly more common in case of information literacy classes, but it is still rather uncommon (5 students, in the case of information literacy classes, and 2 students, in the case of other classes). Only one student uses manaba to collaborate on projects with colleagues (not in an information literacy class).

Other listed functionalities on manaba were: checking course information and changes, reading news and taking tests.

The third section of the questionnaire contained 5 open-ended questions, with the last one allowing the respondents to include any comments, suggestions or critiques with regard to the experimental class.

When asked their opinion about the most useful functionality of manaba in the context of information literacy classes, the vast majority of students listed the possibility of downloading the course materials, anytime, anywhere. One student mentioned the assignment reminder function as one of the most useful ones.

With regard to the most useful functionality in general (regardless of the class), access to course materials was equally listed alongside assignment submission. It is worth mentioning at this point that for the current information literacy classes, there was only one assignment, thus the students did not have many opportunities to make use of this functionality in the course of these classes.

Communication with the class instructors was also listed by several respondents, both in the context of information literacy classes and in the context of other classes.

One other open-ended question asked the students what features they would like to have in an LMS (added to manaba, for instance). Interestingly, several participants responded that they would like to have a "forum" function. This functionality can already be found in manaba, but it was never used by the students; moreover, they did not even know that it existed. The above answers, along with the results from the previous section, can offer the instructors an idea of the most important and useful features of an LMS, as they can be applied to various classes in general, and to computer literacy classes in particular.

In order to be able to organize more effective computer literacy classes, it is important to know what the students find appealing, interesting and useful. The questionnaire allowed them to suggest ideas of organizing such a mandatory computer literacy class; these suggestions and their perspective on the current classes can constitute a basis for future classes. They proposed the use of more visual aids, interactive class activities, presentation of blogs, even games, reflecting current younger generation preferred activities in general. Last, but not least, the "other comments" section provided the opportunity for several students to express once again their enthusiasm for the experimental class, stating that its interactive and non-usual style made it more enjoyable and engaging than the other, regular classes.

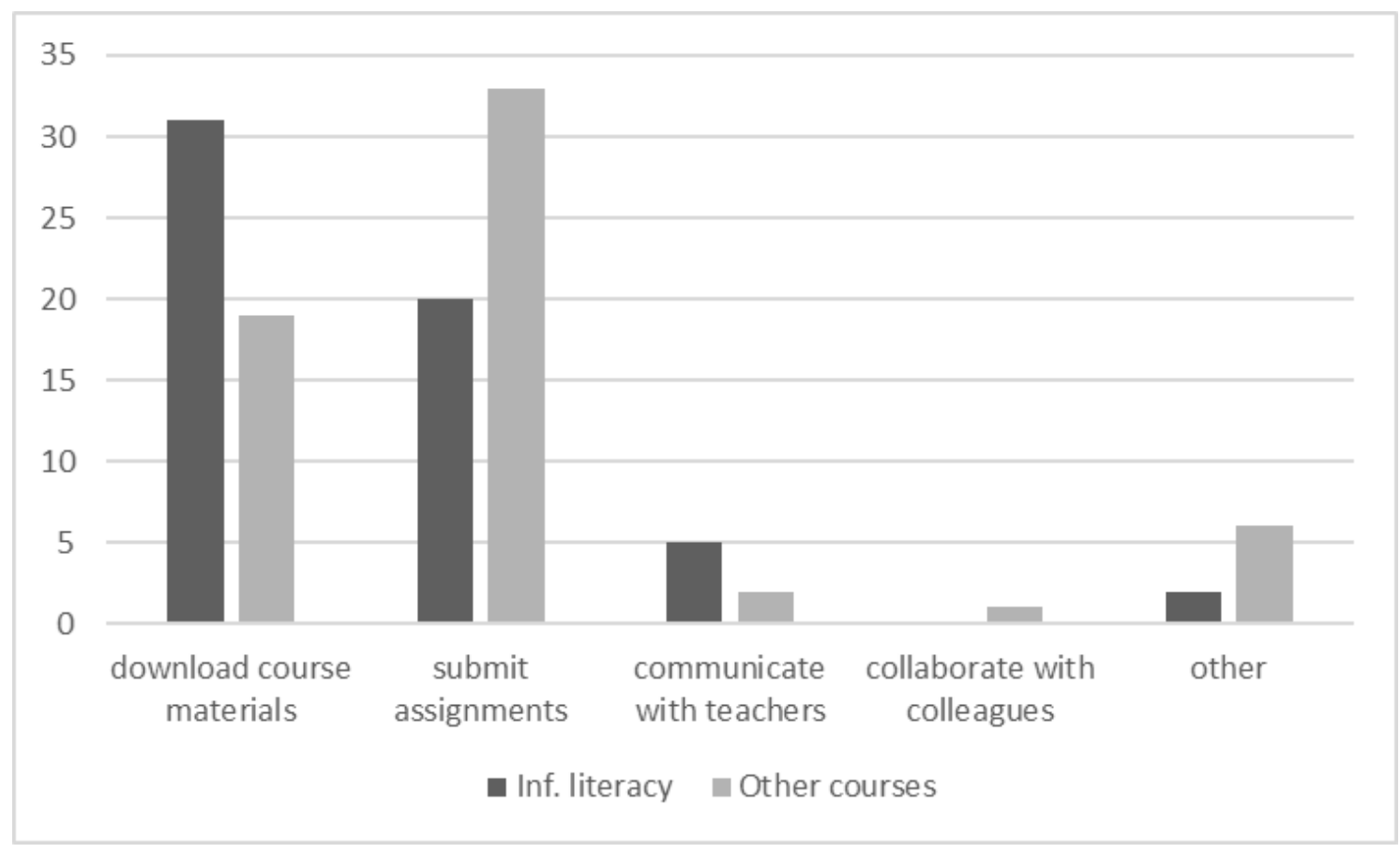

Figure 3. Functionality mostly used on manaba (information literacy courses vs. other courses) 


\section{Conclusions and Future Work}

This paper identified students' perceptions of various styles of teaching computer literacy classes. At the same time, it emphasized the LMS functionalities that these students find most useful, along with the functionalities they most often use.

This work can be significant for the computer literacy education at the university level in an international environment. In the current internationalization context, the needs of students from various backgrounds, local or coming from abroad, with various levels of knowledge and experience, and each with their particular cultural baggage, can be taken into consideration.

Future work directions could focus on identifying culturally sensitive aspects of computer literacy education, by observing connections between cultural backgrounds of students and their preferences in teaching styles.

\section{REFERENCES}

[1] Hoffman, M. \& Blake, J., 2003. Computer literacy: today and tomorrow. Journal of Computing Sciences in Colleges, 18(5), pp. 221-233.

[2] Poynton, T.A., 2005. Computer literacy across the lifespan: a review with implications for educators. Computers in Human Behavior, 21(6), pp.861-872.

[3] Tsai, M.-J. (2002). Do male and female students often perform better than female students when learning computers?: A study of Taiwanese eight graders' computer education through strategic and cooperative learning. Journal of Educational and Computing Research, 26 (1), pp. 67-85.

[4] Wada, T. \& Takahashi, H. (2012). Quantitative Analysis of Computer Literacy Class. INTED2012 Proceedings, 5788-5793.

[5] Parrish, P., \& Linder-VanBerschot, J. (2010). Cultural dimensions of learning: Addressing the challenges of multicultural instruction. The International Review of Research in Open and Distributed Learning, 11(2), 1-19.

[6] William R. Watson \& Sunnie Lee Watson. An argument for clarity: what are learning management systems, what are they not, and what should they become?. TechTrends, Springer Verlag, 2007, 51(2), pp. 28-34.

[7] Chung, C. H., Pasquini, L. A., Allen, J. M., \& Koh, C. E. (2012, October). A Review of Web-based Learning Management System Design on Higher Education. In World Conference on E-Learning in Corporate, Government, Healthcare, and Higher Education (Vol. 2012, No. 1, pp. 1428-1436).

[8] Basioudis, I. G., De Lange, P., Suwardy, T. \& Wells, P. (2007). Accounting students' perceptions of a Learning Management System: An international comparison. Proceedings AAFAANZ Conference, Gold Coast, Australia.

[9] manaba course - Education Support Service, Asahi Net, Inc. (n.d.). Retrieved from http://manaba.jp/en /products/course/

[10] Vasilache, S. (2015). Cultural Dimensions of Using a Learning Management System by Non-native English Speaking International Students in Japan. Journal of Advanced Distributed Technology, 3(7), 39-50. 